\title{
Self-Reported Arrests Among Indigenous Adolescents: a Longitudinal Analysis of Community, Family, and Individual Risk Factors
}

\author{
Kelley J. Sittner ${ }^{1} \cdot$ Kari C. Gentzler ${ }^{2}$
}

Received: 24 January 2016 /Revised: 30 August 2016 / Accepted: 9 September 2016 /

Published online: 20 October 2016

(C) Springer International Publishing AG 2016

\begin{abstract}
Purpose North American indigenous (American Indian/Canadian First Nations) adolescents are overrepresented in the juvenile justice systems in the USA and Canada. One explanation advanced for disproportionate numbers of racial and ethnic minorities in the justice systems is the unequal distribution of risk factors across groups. The purpose of this study is to investigate the prevalence of and risk factors for first arrest within a population sample of indigenous adolescents.

Methods The data come from an 8-year longitudinal panel study of indigenous youth $(n=641)$ from the northern Midwest and Canada, spanning ages 10 to 19 years. We used a discrete-time survival model to estimate the overall hazard of first arrest and change in the arrest hazard over time and included both time-invariant and time varying risk factors.

Results The risk of arrest increased over time, although the largest increase occurred between waves 3 and 4, when the adolescents averaged 13.1 and 14.3 years, respectively. The youth had a $55 \%$ probability of being arrested at least once by the end of the study. Of the time-invariant risk factors, exposure to violence, parent arrest, age, and income were associated with overall risk of first arrest. Three time-varying risk factors (alcohol use, marijuana use, and peer delinquency) were associated with changes in the risk of first arrest.
\end{abstract}

Kelley J. Sittner and Kari C. Gentzler would like to thank Heather McLaughlin, Monica Whitham, Chad Malone, Dane Hautala, and the very helpful anonymous reviewers for their comments on an earlier draft of this article.

\section{Kelley J. Sittner}

kelley.sittner@okstate.edu

1 Department of Sociology, Oklahoma State University, 431 Murray Hall, StillwaterOK 74078 Oklahoma City, USA

2 Department of Sociology, Doane College, Lincoln, USA 
Conclusions Being arrested carries significant repercussions for young people, including involvement in the juvenile justice system as well as consequences into adulthood. Communities must go beyond programs that target problem behaviors because community, family, and peer factors are also important.

\section{Keywords American Indian · Self-report · Arrest · Hazard Analysis}

The overrepresentation of racial and ethnic minority youth in the juvenile justice system in the USA and Canada has garnered increasing attention from researchers, government officials, and criminal justice agencies [46]. Most of the attention has been directed at African American youth; findings suggest that the number of these youth in the juvenile justice system is disproportionate to their number in the general population [19]. North American indigenous adults and juveniles are also overrepresented in the criminal and juvenile justice systems [5]. Between 2011 and 2015 in the USA, the number of indigenous adults in the federal offender population increased by $18.2 \%$ [86]. Additionally, American Indian/Alaska Native youth are committed to residential placement more than two and a half times as often as their white counterparts [36]. A similar pattern of overrepresentation exists in Canada, where Aboriginal people constitute $17 \%$ of those detained in federal institutions but make up only $2.7 \%$ of Canada's population [16].

There is little agreement on why minority groups are overrepresented in the justice systems [46], although multiple explanations have been advanced. These include differential police patrol in poor and minority neighborhoods [26, 27], the greater involvement of minority youth in criminal behavior [76], and racial bias in juvenile and criminal justice systems [87]. Findings on police-juvenile interactions and race are mixed, with nearly all of the studies focused on African American youth (for a review see [54]). Some studies find evidence that race plays a significant factor in juvenile arrests [41], yet others uncover no evidence of discrimination [68]. An additional explanation for minority overrepresentation is that risk factors for offending and arrest are not equally distributed across groups, with some groups experiencing more risk factors than others [77].

The current study focuses on risk factors for arrest, which is usually the first point of contact with the juvenile justice system. Police have several options available when they suspect juveniles of engaging in unlawful behavior, ranging from informal options such as issuing a warning to formal actions like arrest. Arrest is most likely when adolescents are suspected of committing more serious and violent offenses. Evidence also suggests that officers' decisions to arrest are also influenced by characteristics of juveniles unrelated to offense seriousness [5]. The decisions made early in the process, including whether to arrest a juvenile, contribute to overrepresentation at later stages [6]. For instance, American Indian youth were not overrepresented in 2010 arrest statistics, but they were $30 \%$ more likely to be referred to court, $10 \%$ more likely to be detained before trial, and $60 \%$ more likely to be waived to criminal court [70]. Whereas the body of literature on risk factors for juvenile delinquency is vast $[37,58]$, the literature on risk factors for juvenile onset of arrest is considerably smaller and research on risk factors for arrest specifically among indigenous youth is nearly nonexistent. Understanding those risk factors is key to identifying areas for prevention and intervention, and thus reducing the overrepresentation of indigenous youth in the juvenile justice system. 
In the current study, we investigate the prevalence of and risk factors for arrest among a longitudinal sample of indigenous adolescents, spanning the ages of 10 to 19 years. Given the sparseness of literature on this population, we aim to be as specific as possible when referring to juvenile delinquency (i.e., behavior) versus any criminal justice system involvement versus arrest. Additionally, we situate the small body of literature on indigenous youth within the broader juvenile delinquency/juvenile justice literature. Our aim is not to compare arrest rates and risk factors of indigenous youth to other youth, but rather to understand the cultural, community, family, and individual contexts of arrest for this sample.

\section{Theoretical Framework}

Two theoretical perspectives guide the current study. First, we adopt a developmental approach to understand how the risk factors for arrest change in prevalence and importance during adolescence, as well as how arrest itself impacts adolescent development. Adolescence is a period of increasing autonomy and independence from parents and is often characterized by temporary, episodic involvement in delinquent behavior [56] and experimentation with substance use [55]. To at least some extent, these are both part of an overall normative trajectory of development in which most adolescents age out of delinquency [56] and resume law-abiding behavior. As it relates to arrest, however, delinquent and substance using behavior may also propel one toward juvenile justice system involvement, a turning point capable of altering trajectories by increasing offending and re-arrest [39] and negatively impacting future opportunities [75]. Research examining the importance of timing of arrest on outcomes finds that the age at which youth first become involved in the juvenile justice system has differential effects on their development. For example, Wiley [92] found that arrest had more pronounced consequences on later delinquent behavior for younger (e.g., seventh grade) compared to older (e.g., eighth and ninth grade) youth. Arrest may be particularly damaging at younger ages and have more serious consequences later in life, including more chronic offending and longer criminal careers [63], dropping out of school [47], later poverty [61], substance use, and unemployment [50].

The second theoretical perspective is the model of North American indigenous adolescent development recently proposed by Whitbeck et al. [90]. Indigenous youth who grow up on reservations and reserves do so in very unique environments. A history of colonization and subordination has created a contemporary Fourth World status [88]. Many experience persistent poverty and significant health disparities, and as noted above, high rates of justice system involvement. They often are geographically isolated. Yet, these reservations and reserves are also sovereign, self-governing entities that operate their own schools, police departments, and courts. They serve as their respective cultural centers that protect and maintain traditional language, worldviews, and ways of life. It is important to acknowledge these differences from the majority of culture and to consider the historical, community, family, and individual contexts that are unique to indigenous youth.

Together, these perspectives are used to integrate the risk factors arising from normative developmental changes during adolescence with the community and family risk factors that may operate differently within a reservation-based indigenous culture. 
We used this framework to explore select community, family, and individual risk factors for arrest for indigenous adolescents.

\section{Literature Review}

\section{Individual Risk Factors for Arrest}

As stated earlier, adolescence is often accompanied by increases in delinquency, substance use, and delinquent peers. These have each also been associated with criminal arrest. We begin with aggressive delinquency. In 2012, violent crime index arrests accounted for $4.4 \%$ of all juvenile arrests in the USA, and other assaults accounted for an additional $12.9 \%$ [32]. As offense seriousness increases, so does the certainty of arrest [40], and prior record and seriousness of the offense are the primary factors associated with juvenile justice system involvement [10, 20]. For example, juveniles who carry a weapon for protection are more likely to have been arrested than are youth who do not carry one [89]. Little attention has been paid to delinquency among indigenous youth, although there are some indication rates of violence and offending are high. Yessine and Bonta [93] found a slightly larger proportion of chronic offenders among the indigenous youth (versus non-indigenous) in their sample of Canadian youth on probation. Additionally, more of the indigenous youth in the Youth Risk Behavior Surveillance Survey reported carrying a gun in the past month and were more likely to be threatened with a weapon at school, compared to the African American youth in the sample [11].

The second individual risk factor for juvenile arrest is substance use, which is against the law for minors and may contribute to other delinquent behavior [91]. In 2011, arrests for drug and alcohol offenses accounted for $10 \%$ of all juvenile arrests [69]. In the 2002 Profile of Jail Inmates, alcohol use was common among jailed offenders, with $40 \%$ reporting alcohol use at the time they committed their offense [42]. Additionally, compared to non-justice involved youth, larger proportions of youth in the justice system have substance use disorders [22], particularly alcohol and marijuana use disorders [83]. Despite wide variations in substance use patterns among indigenous people [67], indigenous youth are more likely to be arrested for substancerelated offenses than are youth belonging to any other racial or ethnic group in the USA $[32,65]$. Just as the War on Drugs led to harsher punishments of African Americans $[15,43]$, stereotypes regarding indigenous substance use, particularly alcohol use, may lead to more punitive responses by police officers. For example, Beauvais [4] estimated that one-quarter of the reservation-dwelling indigenous high school seniors had been arrested for alcohol offenses, compared to $7 \%$ of white high school seniors in his sample. Importantly, substance use remains a risk factor for arrest into adulthood in many indigenous communities [53].

The third individual risk factor associated with arrest is delinquent peers. It is a consistent correlate of delinquent behavior in a vast number of studies, even though the mechanisms responsible for that association are less clear. Peers may influence delinquent behavior, already delinquent youth may select into delinquent peer groups, or there may be a reciprocal relationship involving a combination of the two [24, 51]. Yet when it comes to arrest, associating with peers who are known to be delinquent may 
have a different effect, independent of a juvenile's own behavior [18]. For instance, Morash [57] argues that peer group characteristics influence whether a police officer views a juvenile as delinquent, and juveniles who associate with peers who have come into contact with police or been arrested are themselves more likely to be arrested. This may be an even more salient risk factor for indigenous youth growing up in small and impoverished reservation communities. Although social network research is still lacking for indigenous youth, disadvantaged communities, even rural ones, are less equipped to prevent deviant peer group formation [79]. Furthermore, the higher density of acquaintances in small communities [34] may reduce anonymity, making the reputations of juveniles more public.

Although not specific to adolescence, strong and consistent gender differences in arrest have been noted. Males, both adult and juvenile, are arrested in greater numbers than are females [7, 32, 69]. This discrepancy has largely been attributed to males' greater involvement in criminal activity [80]. But, the gender gap in juvenile justice system involvement may be smaller for indigenous youth. For instance, the male/female ratio of juveniles in secure confinement in Canada was approximately 7.6:1 for non-indigenous youth and 5.1:1 for indigenous youth [48]. Despite a higher arrest rate for indigenous females than for white females, being male is still a significant risk factor for arrest.

\section{Community and Family Risk Factors for Arrest}

A developing body of research highlights the importance of community context in understanding juvenile delinquency and justice system involvement. For instance, Rodriguez [72] found that youth living in highly disadvantaged communities were more likely to face harsher treatment in the juvenile justice system, compared to youth from more advantaged areas. Prior research has shown that poor communities, particularly minority communities, have higher rates of incarceration [71, 75]. Furthermore, economically disadvantaged neighborhoods are also associated with higher rates of delinquent behavior and substance use among youth [49]. McCord et al. describes this as "growing up in a context of risk" ([54]:238). Many reservations and reserves are characterized as among the most disadvantaged communities, with high rates of poverty and an average unemployment rate hovering around $50 \%$ [8].

In addition to low socioeconomic status, community violence is also associated with higher rates of criminal justice system involvement. Youth who are exposed to violence, either witnessed or experienced, are more likely to engage in delinquent and violent behavior themselves [13], which places them at increased risk of being arrested. In their study of criminal behavior among a diverse, representative sample of young adults, Eitle and Turner [23] found that much of the effect of race on criminal behavior could be explained by the higher levels of African Americans' exposure to community violence. Indigenous adolescents living on reservations encounter comparatively high rates of violence [3], and indigenous people report rates of violent victimization that are approximately twice the national average [35]. In Canada, indigenous people are also overrepresented in victimization statistics [12].

Research on the transmission of criminal behavior in families consistently links parent and child antisocial behavior [29, 30, 84], although the strength of the associations vary. Research specifically examining the relationship between parent and child 
criminal justice system involvement is less extensive but generally finds parental involvement predicts child involvement. For instance, Rowe and Farrington [74] showed that the adult males in their sample whose parents had histories of criminal convictions were more likely themselves to be convicted. Youth whose parents have criminal histories may also be more likely to receive harsher treatment within the juvenile justice system. In their study of juvenile court data in Maricopa County, Arizona, Rodriguez et al. [73] found that youth with a father who had been incarcerated were significantly more likely to receive out-of-home placement than are youth whose father had no incarceration history, after controlling for offense severity and prior record. Farrington [28] suggests many possible mechanisms to explain why parental involvement in the criminal justice system predicts child involvement, including genetic transmission, environmental risk factors, and bias in the juvenile and criminal justice systems. It is possible that in small, relatively close-knit communities such as those found on rural reservations and reserves, police officers know or are familiar with the criminal histories of many juveniles' families, which may factor into the arrest decision.

Family structure also impacts police officers' decisions. Youth from single-parent households are more likely to be arrested than are those from two-parent households $[38,45]$. In a meta-analysis of juvenile recidivism by Cottle et al. [17], living in a single-parent home was predictive of re-arrest. On the other hand, it may also be due to the elevated levels of delinquency among juveniles from single-parent homes [2]. Single parents are less able to effectively monitor children's behavior and/or are at greater social and economic disadvantage, which are each associated with delinquent behavior [64]. Yet, family structure often looks quite different among indigenous communities, where extended kinship ties and living arrangements mean that youth are parented by many family members, not just biological parents. These familial arrangements may buffer the negative aspects that single parenting can have.

\section{The Use of Self-Reported Arrests}

The present study utilized self-reported adolescent arrests, which have two important limitations. First, juveniles may not accurately understand the situation and confuse outcomes such as station adjustments or citations with being arrested. Second, what follows the arrest is not reported (e.g., acquittal, diversion, incarceration). However, research on the validity and reliability of self-report delinquency measures generally supports their use [85]. Other research has explored the extent to which self-reports are valid and reliable among different populations of juveniles (e.g., white vs. black, male vs. female), but findings are inconsistent [29, 30, 44]. For example, Farrington et al. $[29,30]$ found some racial differences although they varied depending on the measure tested: validity was higher for admitting offenses for white youth but higher for admitting arrests for African American youth. Yet, official reports are not without their shortcomings. Notably, official data have been found to overestimate differences in offending between African American and white youth [7, 24].

In spite of limitations, using self-reported arrest data offers some important advantages. Longitudinal self-report data make it possible to identify the age of first arrest and the cumulative risk of arrest that cannot be achieved using aggregate arrest data. Furthermore, although arrest that leads to conviction and, in the most serious 
circumstances, incarceration is arguably very detrimental to youth, being arrested itself is accompanied by immediate and longer-term consequences and is worthy of attention [7].

\section{The Current Study}

Being arrested in adolescence represents a powerful turning point in development, including promoting more delinquent behavior and adversely affecting mental health and relationships, with consequences that resonate over the life course. A growing body of research has examined the overrepresentation of racial and ethnic minority youth in the juvenile justice system, primarily directed at African Americans. We extend this important line of inquiry to North American indigenous youth, who are also overrepresented but are relatively understudied. The current study aims to further our understanding of individual and contextual (i.e., community and family) risk factors for arrest, the first step toward involvement with the juvenile justice system and which potentially contributes to overrepresentation at later stages. The data come from an 8-year longitudinal panel study of indigenous youth from the northern Midwest of the USA and southern Canada and spans the course of adolescence (i.e., ages 10 to 19 years). Based on the theoretical framework and literature reviewed above, we offer the following two hypotheses. First, individual risk factors that vary over adolescence (i.e., aggressive delinquency, substance use, and delinquent peers) will be associated with time to first arrest (or onset of arrest). Second, to assess the impact of contextual risk factors, we hypothesize that community and family risk factors will be associated with overall risk of arrest. To test those hypotheses, we estimate hazard models predicting time to first arrest using time-invariant and time-varying risk factors.

\section{Methods}

\section{Data and Sample}

These data were collected as part of an eight-wave longitudinal study designed in partnership with eight reservations and reserves and a university-based research team. The reserves and reservations share a common cultural tradition and language with minor regional variations in dialects. It is among the most populous Native cultures in the USA and Canada. Prior to the application funding, the research team was invited to work on these reservations, and tribal resolutions were obtained. As part of the agreement to work together, the researchers promised that participating reservations would be kept anonymous in published reports. On each participating reservation, an advisory board representing all reservation districts was appointed by the tribal council. The advisory boards were responsible for handling difficult personnel problems, advising on questionnaire development, and reviewing reports for respectful wording. All participating staff on the reservations were approved by the advisory board and were either tribal members or, in a few cases, non-members who were spouses of tribal members. To ensure quality of data collection, all the interviewers underwent special 
training for conducting pencil-and-paper and computer-assisted personal interviewing for the diagnostic measures. The training included practice and feedback sessions.

Each participating tribe provided a list of families of tribally enrolled children aged 10-12 years who lived on or proximate to (within 50 miles) the reservation or reserve. Attempts were made to contact all tribally enrolled families with a target child within the specified age range in order to achieve a population sample. Families were recruited through a personal visit by an interviewer in which the project was explained to them. They were presented with a traditional gift and were invited to participate. If a family agreed to be interviewed, each family member received $\$ 40$ for his or her time when the interviews were completed. The recruitment procedure resulted in an overall response rate of $79.4 \%$, or 746 of the original 940 families contacted. Annual retention rates were as follows: $94.8 \%$ wave $2,93.2 \%$ wave $3,88.2 \%$ wave $4,90.1 \%$ wave 5 , $87.8 \%$ wave $6,84.6 \%$ wave 7 , and $79 \%$ wave 8 . Because one location did not have an active advisory board that could review papers prior to publication, their data were excluded from the current study, reducing the sample size to 674. The target adolescents were ages 10 to 13 years old at baseline, with a sample mean of 11 years. The sample mean ages for the remaining waves were 12.08 years at wave 2, 13.1 years at wave $3,14.3$ years at wave $4,15.3$ years at wave $5,16.2$ years at wave $6,17.2$ years at wave 7 , and 18.3 years at wave 8 .

\section{Measures}

The dependent variable, arrest, was assessed by asking respondents if they had been arrested in the past year. Responses are coded as $0=$ not arrested and $1=$ arrested. Although arrest was measured in all waves of the study, only waves 2, 3, 4, 6, and 8 were used in this paper. Wave 1 was excluded because it referenced having ever been arrested, rather than arrested in the past year. Waves 5 and 7 were excluded due to the data collection design and the lagged nature of the present analysis (see the "Analytic Strategy" section for more details).

\section{Time-Invariant Covariates}

All of the time-invariant covariates were assessed at wave $1 .{ }^{1}$ Two community context variables were included in the analysis. Adolescent exposure to violence was measured with three questions drawn from a checklist of life events. The primary parent/caretaker was asked whether, during the past 12 months, the caretaker was physically attacked or assaulted; witnessed someone being badly injured or killed; or was threatened with a weapon, held captive, or kidnapped. Affirmative responses were summed into an index of exposure to violence (Cronbach's $\alpha=0.66$ ). A measure of community violence was assessed by asking parents/caretakers to report whether 11 violent events (e.g., violent argument between neighbors, gang fight, robbery, murder, vandalism) happened in their community during the past year. This measure is similar to that used in the Family

\footnotetext{
${ }^{1}$ Each of the community variables as well as parent arrest were first tested to determine whether they had time-varying relationships with time to first arrest, which none did (results available upon request). There were associations with overall arrest risk, however, and they were included as time-invariant predictors at wave 1.
} 
and Community Health Study (see [81]) and adapted by our project's advisory boards. Responses for each event were coded such that $0=$ never, $1=$ sometimes, and $2=$ often. A composite measure was created by averaging responses to the 11 items, with higher scores reflecting more community violence (Cronbach's $\alpha=0.92)$.

We included two family variables reported by parent/caretakers. Single-parent households were indicated by a dichotomous variable where $1=$ single parent/ caretaker and $0=$ two parent/caretaker. Parent arrest was a dichotomous indicator of whether at least one parent/caretaker reported being arrested in the past 12 months, coded $1=$ arrested and $0=$ not arrested.

One individual time-invariant risk factor was included. Gender was dichotomized and coded as $0=$ female and $1=$ male. We controlled for age, per capita family income, and location. Initial age is a continuous measure of adolescent age in years. Per capita family income was measured by asking parents/caretakers to indicate their overall household incomes in the past year. Responses were divided by the number of people living within the household, which was then divided by 1000 to set the metric of this measure in thousands of dollars. Although all of the communities in the study share a common cultural heritage, about $16 \%$ of the sample lives on First Nation reserves in Canada and $84 \%$ live on US reservations. To control for possible justice system differences between the two countries, we include a dichotomous country indicator where $1=$ Canada and $0=$ USA. $^{2}$

\section{Time-Varying Covariates}

All time-varying covariates were assessed at waves 1, 2, 3, 5, and 7 .

Peer delinquency was assessed by asking the adolescents if any of their three best friends had gotten in trouble with the police. Responses were coded such that $0=$ no and $1=$ yes.

Our measure of aggressive delinquency was taken from the Diagnostic Interview Schedule for Children IV [78]. Adolescents were asked if they had done any of the following in the past 12 months: threatened or frightened someone on purpose; been in a physical fight in which someone was or could have been hurt; started a physical fight in which someone was or could have been hurt; tried to hurt someone badly or been physically cruel to someone; hurt someone with a weapon; and threatened someone with a weapon. Responses were coded such that $0=$ no and $1=$ yes and were then summed into an overall index of aggressive delinquency (Cronbach's $\alpha=0.68$ to 0.71 ).

Two indicators of substance use were included. Alcohol use was assessed by asking adolescents if they had ever had a sip of wine, beer, or liquor. Of those who answered affirmatively, a follow-up question was asked regarding drinking alcohol in the past year. The variable was coded such that $0=$ no alcohol use in the past year and $1=$ alcohol use in the past year. Marijuana use was assessed by asking adolescents if they had ever smoked marijuana (pot). Of those who answered affirmatively, a followup question was asked about their marijuana use during the past 12 months. The variable was coded such that $0=$ no marijuana use in the past year and $1=$ marijuana use in the past year.

\footnotetext{
${ }^{2}$ Indigenous people on reservations/reserves are subject to multiple levels of criminal justice jurisdiction beyond federal, including state, county, and tribal which are not controlled for in the current study.
} 


\section{Analytic Strategy}

To assess the overall hazard probability of first arrest as well as the change in the probability over time, using both time-stable and time-varying predictors of arrest, we employed a discrete-time survival model, also known as event history analysis or time-to-event analysis, using Mplus version 6 [60]. In Mplus, this is estimated as a single-class latent variable mixture model, using arrest at each wave as observed indicators of a single latent factor, with the factor loadings fixed to 1 and the factor variance fixed to 0 (for full details, see [59]). The model is depicted in Fig. 1. The latent variable represents the base hazard rate, or risk of being arrested during the study. The latent factor was predicted as a logistic function of the time-invariant covariates (e.g., path included from adolescent gender to the latent factor). In addition, a hazard function for each individual wave was predicted as a logistic function of the time-varying covariates by including paths from each time-varying covariate at the preceding wave to arrest at the immediately following wave (e.g., time-varying covariate at wave 1 to arrest at wave 2). The hazard is the probability of experiencing arrest for the first time in a given wave. For the lagged analysis, we include time-varying covariates at waves $1,2,3,5$, and 7 (these variables were not measured at waves 4 or 6 ) and the arrest variables at waves $2,3,4,6$, and 8 .

Missing values were indicated with the value of -99 , which is used in Mplus as a means of right-censoring variables in survival analysis. Responses that were missing due to participant non-response also were coded as -99 . In the absence of a previous arrest (i.e., a value of 1 at a prior wave), Mplus treats -99 values as true missing responses, and responses are not right-censored. All models were estimated using full information maximum likelihood estimation with the expectation maximization algorithm to account for

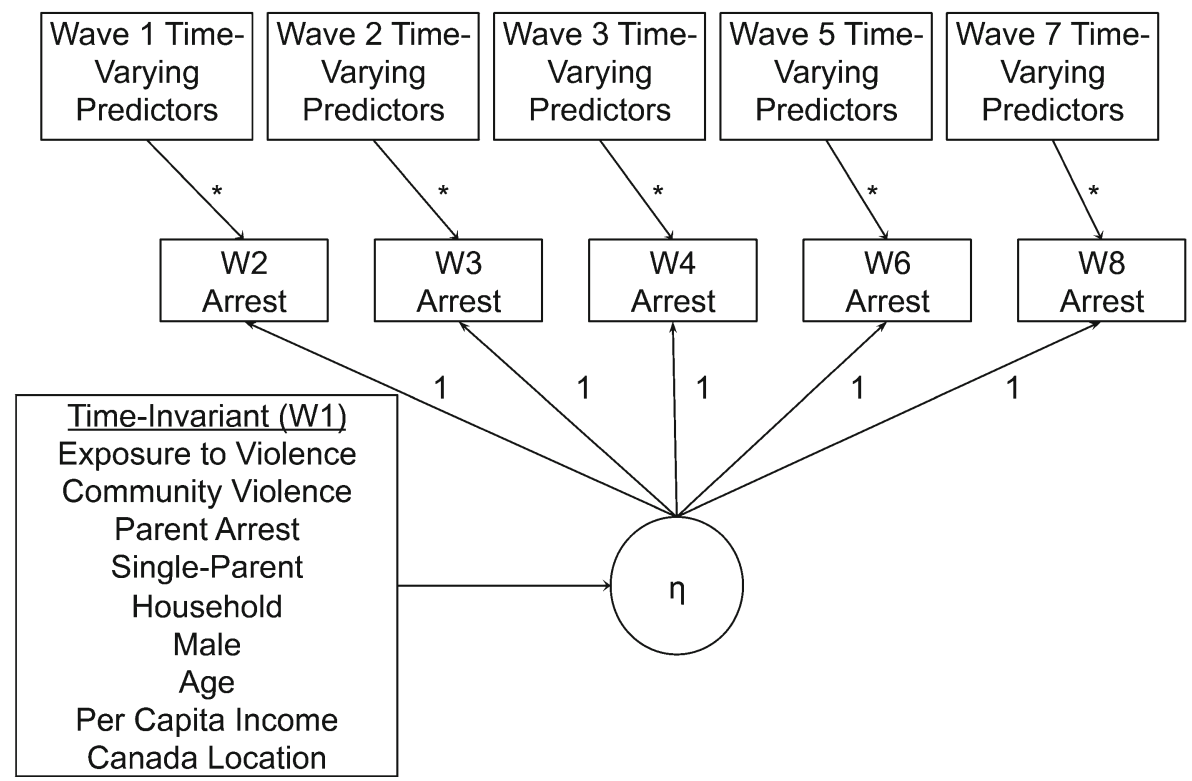

Fig. 1 Discrete time hazard model predicting first arrest. Time-varying covariates at each wave were aggressive delinquency, alcohol use, marijuana use, and peer drinking 
(non-censored) missing responses. The final analytic sample consisted of 641 cases of the original 674 participants $(95.1 \%)$. Thirteen cases were excluded because they reported being arrested at or prior to wave 1 (see below), and an additional 20 cases had missing data on the exogenous variables (i.e., age, gender, and per capita family income). Missing data analysis found no differences between included versus excluded cases on any of the baseline variables used in the analysis.

We conducted a series of model comparison tests to determine whether the associations between each of the time-varying covariates and arrest varied over time. We first estimated a model in which the path coefficients from aggressive delinquency to subsequent arrest were allowed to estimate separately across the waves (unconstrained model). We then estimated a model in which the paths for aggressive delinquency were constrained to be equivalent across the waves (constrained model). If the two models provided a statistically equivalent fit to the data, the constrained model would be preferred, as it indicates that the relationship between aggressive delinquency and subsequent arrest was not moderated by time and it more parsimoniously describes the data. Model fit comparisons were made using the $-2 * \log$-likelihood change test $(-2 \Delta \mathrm{LL})$. We repeated the test by stepping in the remaining time-varying covariates. In all cases, the constrained models provided a statistically equivalent fit to the unconstrained models (Table 1) and were thus selected for the analyses.

\section{Results}

\section{Descriptive Analyses}

In the first wave of the study (mean age $=11.1$ years), only 13 youth reported having ever been arrested. Because this paper is concerned with the timing of first arrest, these adolescents were excluded from further analyses. The small number of youth who were arrested at wave 1 prevents us from making statistical comparisons with those who were not, but a descriptive analysis suggests that, compared to the adolescents who did not report being arrested at wave 1, larger proportions of the arrested youth lived in a single-parent household (53.9 vs. $27.6 \%$ ), reported using alcohol (46.2 vs. $5.1 \%$ ) and marijuana (30.8 vs. $5.2 \%$ ) in the past year and had at least one best friend who had gotten into trouble with the police (61.5 vs. $26.7 \%$ ). They also reported engaging in more aggressive delinquency than the youth who were not arrested in wave 1 (3.08 vs. 1.16). Arrested youth had a lower

Table 1 Model comparisons

\begin{tabular}{lllllc}
\hline & $\begin{array}{l}\mathrm{LL} \\
\text { unconstrained }\end{array}$ & $\begin{array}{l}\mathrm{LL} \\
\text { constrained }\end{array}$ & & $-2 \Delta \mathrm{LL}$ & $\Delta d f \quad p$ value \\
\hline $\begin{array}{l}\text { Model 2a: adding time-varying aggressive } \\
\text { delinquency }\end{array}$ & -5748.453 & -5750.018 & 3.130 & 4 & 0.54 \\
$\begin{array}{l}\text { Model 2c: adding time-varying alcohol use } \\
\text { Model 2d: adding time-varying marijuana use }\end{array}$ & -6834.573 & -6838.022 & 6.898 & 4 & 0.14 \\
Model 2e: adding time-varying peer deliquency $^{\mathrm{a}}$ & -9096.590 & -9097.869 & 2.558 & 4 & 0.63 \\
\hline
\end{tabular}

a Time-varying variables tested in previous model are constrained in the present model 
average per capita family income than did non-arrested youth (\$3869 vs. \$5571). In sum, although representing a small proportion of the sample, those youth who reported being arrested at the first wave of the study had more risk factors than the youth who did not report being arrested.

Beginning in wave 2, adolescents were asked if they had been arrested in the past year. The percentage of youth who reported being arrested, shown in Fig. 2, increased over the course of the study, with slight fluctuations occurring in the middle waves. At wave 2 (12.1 years), only $6.3 \%$ youth reported a past-year arrest, compared with a high of $22.4 \%$ in wave 6 (mean age $=16.2$ years). Many of the adolescents reported being arrested in multiple waves (not shown), with almost one-quarter $(24.2 \%$ ) arrested more than once during the study.

Characteristics of the analytic sample are provided in Table 2. All time-invariant covariates come from wave 1. Exposure to violence was low, 0.25 (out of 3), as was community violence, 0.91 (out of 2). Over $10 \%$ of parents/caretakers reported having been arrested on their wave 1 survey. At wave 1, the sample was $49.6 \%$ male and was between 9 and 13 years, with a mean age of 11.07 years. Overall income was low, with a per capita family income of $\$ 5571$. Time-varying covariates are provided at the bottom of Table 2 . The percentages of adolescents using substances and who had peers in trouble with police increased steadily over the study, but aggressive delinquency decreased at wave 7 following a peak at wave 5 .

\section{Hazard Analysis of Arrest}

Before including covariates, we began by estimating an unconditional hazard model of first arrest, the results of which are presented in Fig. 3. The solid line represents the hazard probability of first arrest in a given wave. The largest increase in the probability of being arrested for the first time occurred between waves 3 and 4 . Adolescents had a $15 \%$ probability of first arrest in wave 8 . The dashed line represents the cumulative probability that an adolescent would be arrested for the first time by a particular wave. For example, by wave 6 , the probability that a youth would have been arrested was nearly 0.40 . By the final wave of the study (ages 17 to 20 years old), these indigenous youth had a $55 \%$ probability of being arrested at least once.

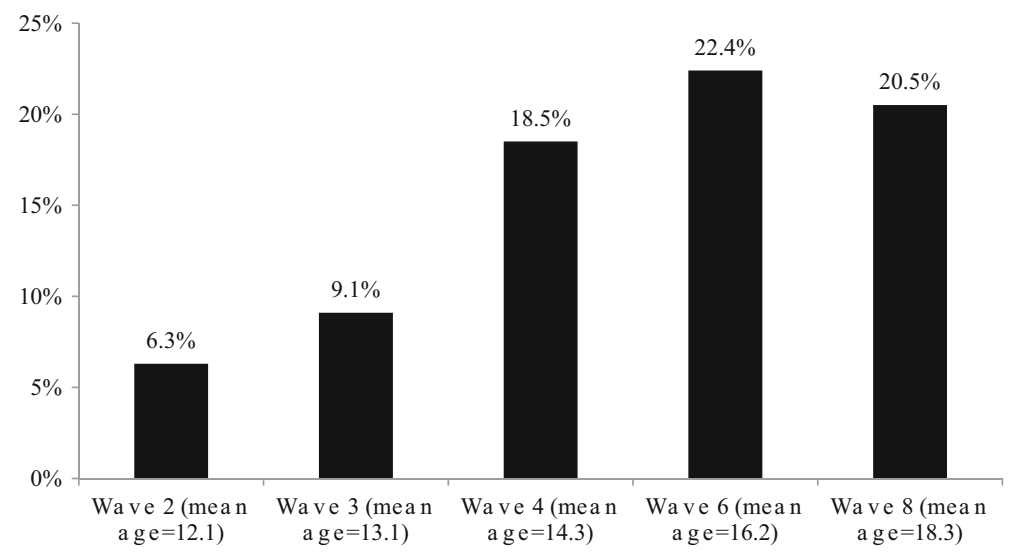

Fig. 2 Percent of youth reporting arrest in the past year 
Table 2 Descriptive statistics of analytic sample

\begin{tabular}{|c|c|c|c|c|c|c|}
\hline & Number & $\mathrm{M} / \%$ & SD & Min & Max & $\alpha$ \\
\hline \multicolumn{7}{|l|}{ Time-invariant variables, W1 } \\
\hline Exposure to violence ${ }^{\mathrm{a}}$ & 641 & 0.25 & 0.58 & 0 & 3 & 0.66 \\
\hline Community violence $^{\mathrm{a}}$ & 623 & 0.91 & 0.55 & 0 & 2 & 0.92 \\
\hline Parent arrest ${ }^{\mathrm{a}}$ & 639 & $10.49 \%$ & & & & \\
\hline Single parent ${ }^{\mathrm{a}}$ & 641 & $27.30 \%$ & & & & \\
\hline Male & 641 & $49.61 \%$ & & & & \\
\hline Age & 641 & 11.07 & 0.77 & 10 & 12 & \\
\hline Per capita income ${ }^{\mathrm{a}}$ & 641 & $\$ 5571$ & $\$ 4043$ & $\$ 250$ & $\$ 25,000$ & \\
\hline Location $($ Canada $=1, \mathrm{US}=0)$ & 641 & $15.76 \%$ & & & & \\
\hline \multicolumn{7}{|l|}{ Time-varying variables } \\
\hline Aggressive delinquency, W1 & 641 & 1.17 & 1.56 & 0 & 8 & 0.71 \\
\hline Aggressive delinquency, W2 & 604 & 1.10 & 1.47 & 0 & 8 & 0.68 \\
\hline Aggressive delinquency, W3 & 599 & 1.11 & 1.50 & 0 & 8 & 0.69 \\
\hline Aggressive delinquency, W5 & 577 & 1.17 & 1.57 & 0 & 8 & 0.69 \\
\hline Aggressive delinquency, W7 & 541 & 0.60 & 1.14 & 0 & 8 & 0.68 \\
\hline Alcohol use, W1 & 636 & $5.03 \%$ & & & & \\
\hline Alcohol use, W2 & 596 & $16.61 \%$ & & & & \\
\hline Alcohol use, W3 & 595 & $26.55 \%$ & & & & \\
\hline Alcohol use, W5 & 576 & $50.52 \%$ & & & & \\
\hline Alcohol use, W7 & 541 & $63.40 \%$ & & & & \\
\hline Marijuana use, W1 & 639 & $5.01 \%$ & & & & \\
\hline Marijuana use, W2 & 603 & $13.10 \%$ & & & & \\
\hline Marijuana use, W3 & 599 & $20.53 \%$ & & & & \\
\hline Marijuana use, W5 & 573 & $39.27 \%$ & & & & \\
\hline Marijuana use, W7 & 543 & $39.41 \%$ & & & & \\
\hline Peer delinquency, W1 & 623 & $26.97 \%$ & & & & \\
\hline Peer delinquency, W2 & 589 & $36.84 \%$ & & & & \\
\hline Peer delinquency, W3 & 585 & $43.08 \%$ & & & & \\
\hline Peer delinquency, W5 & 562 & $58.90 \%$ & & & & \\
\hline Peer delinquency, W7 & 533 & $62.66 \%$ & & & & \\
\hline
\end{tabular}

${ }^{\mathrm{a}}$ Parent/caretaker report

Covariates were added next, beginning with time-invariant covariates predicting overall risk of arrest in model 1 (Table 3). Exposure to violence and parent arrest were positively associated with risk of arrest. Each additional violent event that an adolescent was exposed to increased their risk of subsequent arrest by $36 \%$. Additionally, youths who had a parent with a history of arrest were $70 \%$ more likely to ever be arrested, compared to youths whose parents had no arrest history. Older adolescents at wave 1 had higher odds of being arrested than did younger adolescents. Per capita income was negatively associated with risk of arrest, such that an increase of $\$ 1000$ in per capita family income was associated with $8 \%$ lower odds of being arrested. 


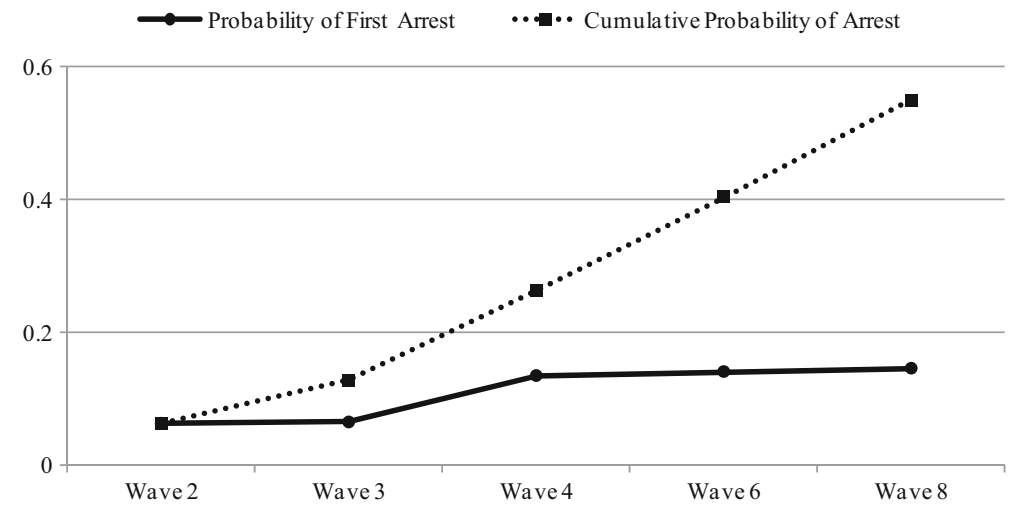

Fig. 3 Unconditional hazard model of arrest

Time-varying covariates were added in model 2. A single set of values is reported for each of the time-varying covariates, as they were statistically equivalent across the waves, and thus had the same values. Exposure to violence, parent arrest, and income remained significant time-invariant covariates in the full model. Male gender became significant after including time-varying influences; being male increased the overall risk of arrest by $39 \%$. Alcohol use, marijuana use, and peer delinquency were significant predictors of subsequent arrest. Compared to those who did not drink alcohol in the past year, adolescents who used alcohol were $93 \%$ more likely to be arrested in the subsequent year. Adolescents who used marijuana were more than twice

Table 3 Hazard models predicting first arrest $(n=641)$

\begin{tabular}{|c|c|c|c|c|c|c|}
\hline & \multicolumn{3}{|c|}{ Model 1} & \multicolumn{3}{|c|}{ Model 2} \\
\hline & $\mathrm{B}$ & $\operatorname{Exp}(B)$ & SE & $\mathrm{B}$ & $\operatorname{Exp}(B)$ & SE \\
\hline \multicolumn{7}{|c|}{ Time-invariant covariates (W1) } \\
\hline Exposure to violence ${ }^{\mathrm{a}}$ & 0.30 & $1.34 * *$ & 0.11 & 0.30 & $1.35^{* *}$ & 0.11 \\
\hline Community violence $^{\mathrm{a}}$ & 0.15 & 1.17 & 0.13 & 0.08 & 1.08 & 0.14 \\
\hline Parent arrest ${ }^{\mathrm{a}}$ & 0.54 & $1.71 * *$ & 0.20 & 0.44 & $1.55^{*}$ & 0.21 \\
\hline Single parent ${ }^{\mathrm{a}}$ & 0.22 & 1.25 & 0.15 & 0.20 & 1.22 & 0.16 \\
\hline Male & 0.26 & 1.30 & 0.14 & 0.33 & $1.39 *$ & 0.15 \\
\hline Age & 0.25 & $1.29 * *$ & 0.09 & 0.08 & 1.08 & 0.10 \\
\hline Per capita income ${ }^{\mathrm{a}}$ & -0.08 & $0.92 * * *$ & 0.02 & -0.07 & $0.93 * *$ & 0.02 \\
\hline Canada location & -0.47 & $0.62 *$ & 0.24 & -0.40 & 0.67 & 0.25 \\
\hline \multicolumn{7}{|l|}{ Time-varying covariates } \\
\hline Peer delinquency & & & & 0.73 & $2.08 * * *$ & 0.16 \\
\hline Aggressive delinquency & & & & 0.08 & 1.08 & 0.05 \\
\hline Alcohol use & & & & 0.66 & $1.93 * *$ & 0.20 \\
\hline Marijuana use & & & & 0.73 & $2.08 * * *$ & 0.19 \\
\hline
\end{tabular}

$* * * p<0.001 ; * * p<0.01 ; * p<0.05$

a Parent-report 
as likely as their peers to be arrested in the subsequent year $(\operatorname{Exp}(B)=2.08)$. Compared to adolescents who did not have a friend that had been in trouble with the police during the past year, youth who had delinquent peers were more than twice as likely to be arrested in the subsequent year $(\operatorname{Exp}(B)=2.08)$. Aggressive delinquency was not significantly associated with subsequent arrest, although it was in the expected direction and approached significance $(p=0.08)$.

\section{Discussion}

Indigenous youth are disproportionately involved in the criminal and juvenile justice systems in the USA and Canada $[1,16]$. We focused our analysis on arrest because it is often the first point of contact with the juvenile justice system and may contribute to overrepresentation at later stages [6]. By the end of the study, half (49.8\%) of the adolescents reported being arrested at least once, with $24.2 \%$ arrested multiple times. The results from a discrete time survival analysis showed that the hazard probability of first arrest increased markedly between waves three and four of the study, when the adolescents averaged 13 and 14 years, respectively. Overall, there was a $55 \%$ probability of being arrested at least once during the study.

Our study was guided by two theoretical perspectives. Using a life-course perspective, we included three individual-level risk factors that vary in prevalence and importance over adolescence. Given that differential involvement in criminal behavior has been suggested as another cause of justice system overrepresentation [76], we considered involvement in delinquent behavior by including measures of aggressive delinquency and substance use (i.e., alcohol and marijuana use). Only the substance use variables were associated with an increased risk of arrest. Indigenous youth are more likely than youth from other racial groups to be arrested for substance-related offenses [65]. This may be a reflection of the effects of substance use, especially alcohol, on behavior [33] and the higher rates and earlier onset of serious substance use among indigenous youth [4, 14]. But, it may also indicate the harsher treatment that indigenous youth experience from justice officials due to the prevalence of negative stereotypes about drinking by indigenous people [52]. In our analysis, even modest levels of substance use, measured as using alcohol or marijuana in the past year, contributed to a higher risk for arrest in subsequent waves. Given the strong linkages between substance use and offending in this study, they likely also indicate other common risk factors not measured in the current study. More attention to identifying developmental pathways to arrest is warranted.

Aggressive delinquency was not associated with subsequent risk for arrest, which was unexpected given arrest should be more likely for more serious offenses. Recent research with this same sample (masked for review) indicates multiple patterns of aggressive delinquency during adolescence, two of which were characterized by high numbers of aggressive acts. The absence of a significant association with arrest is potentially attributable to the differential patterns of aggression within this sample. Given that more serious and repeat offenses are more likely to result in arrest [10, 20, 41], it seems plausible that the most aggressive youth in the current study would face a greater risk of arrest as well.

The third individual-level variable, peer delinquency, specifically having a close friend who had been in trouble with the police, was a significant predictor of being 
arrested in subsequent waves of the study. This finding suggests two explanations: delinquent behavior often occurs in groups and associating with friends who have histories of police contacts may tarnish one's own reputation. Regarding the first explanation, friends on reservations and reserves grow up in the same community contexts as the adolescents in our study and are subject to the same risk factors that we include here. In the small, rural reservation/reserve communities of this sample, police officers are likely to be well aware of the arrest records of the adolescents' family members and friends.

The second theoretical perspective used in the current study is the model of indigenous adolescent development [90], which emphasizes the importance of historical, cultural, family, and individual influences that shape both the adolescents and the risk factors to which they are exposed. It is important to recognize that reservation/reservedwelling North American indigenous adolescents live and develop in very unique contexts compared to most youth. The reservations and reserves are geographically and culturally isolated from other communities, making them different than any other place in the USA or Canada, and in fact, often quite different from one another. Given the high rates of poverty and violence found on many reservations, indigenous youth encounter a disparate number of risk factors, which is one possible explanation for their disproportionate involvement in the juvenile justice systems [77]. To assess the relationship between community context and arrest, we included two different measures of community violence. Only exposure to violence, measured through parent/caretaker reports of experiencing violent victimization at the first wave of the study, was associated with being arrested at least once over the course of the study. Having a parent or caretaker who was a victim of a violent crime makes it more likely that a youth may engage in aggressive behavior [13]. Our findings suggest that, above and beyond their own behavior, exposure to violence also places youth at risk of being arrested. This is important given that youth may become enmeshed in the justice system for reasons other than engaging in drinking or drug use, which can have serious consequences as we discuss below.

We also included family context variables. A small proportion of the adolescents, about one in ten, had at least one parent or caretaker who reported being arrested in the first year of the study, but their risk of being arrested was significantly greater than those youth whose parents/caretakers had not been arrested. This association remained significant after accounting for adolescent behaviors that could lead to arrest. Other studies have documented the intergenerational transmission of criminality [74, 84], which suggests a continuity of behavior from one generation to the next. In addition to intergenerational processes, we suggest, as have others [28], that the negative labels parents receive because of their arrest records may be prospectively applied to their children.

The second family context variable, living in a single-parent/caretaker household, was not related to arrest, which is contrary to other studies [38, 45]. Drawing from the indigenous model of adolescent development, the extended kinship networks and parenting practices that are common among these communities may offset the difficulties faced by single parents. Other family members often are involved in parenting responsibilities, including monitoring and discipline. In other words, coming from a single-parent household may not present the same risk as may be found in nonindigenous cultures. 


\section{Limitations}

There are important limitations to the present study. First, these data come from a single culture of indigenous youth from a limited geographic area in the northern Midwest and southern Canada. The results provide important and in-depth information on risk of arrest, but they may not be generalizable to other indigenous cultures. The sample also is entirely rural and the cultural and community contexts of urban indigenous youth are likely to be quite different. Second, our dependent variable was measured using selfreported arrests, which may not accurately reflect the number of youth who were officially arrested. The adolescents may not distinguish between formal arrests and informal warnings or station adjustments. Furthermore, we were unable to validate selfreports with official reports due to confidentiality agreements with our tribal partners. However, adolescents were asked a screening question regarding being in trouble with the police in the past year prior to being asked if they had been arrested, to differentiate informal versus formal contact. A third limitation was the lack of information on macrolevel risk factors, which prohibited us from examining, for example, whether there were differences in the hazard of first arrest for youth under tribal police jurisdiction versus state or county police jurisdiction.

\section{Conclusion}

Being arrested can bring about significant repercussions, both immediate in the form of entrance into the juvenile justice or criminal justice systems and the possibility of being incarcerated, as well as over the life course. Arrest early in life may be particularly damaging because of its associations with adolescent reoffending [39] and adult criminality [21]. It also contributes to disrupted education [47] and later difficulties in life such as limited employment opportunities and poverty. In relation to this, further research on the consequences of arrest is necessary to identify other potential consequences that may be unique to reservation/reserve communities given the overall lack of attention to this group. For example, many of these communities already have high unemployment and persistent poverty, and a criminal record may not be as stigmatizing.

The current study has important implications for our indigenous community partners as well as researchers and criminal justice agencies. General risk domains important to early justice system involvement among youth (i.e., individual, peer, family, community) $[31,82]$ are represented among our population but in some cases, specific risk factors within those domains differ. Neither community violence nor single-parent household was related to juvenile arrest in this sample, although caretaker exposure to violence increased the overall risk of arrest. More research with indigenous samples is needed to identify additional risk factors related to the cultural, community, and family context of adolescent development.

Developing prevention and intervention programs that target illegal and delinquent behaviors (i.e., substance use and delinquency) will reduce behaviors that lead to involvement with the police, which is important for healthy adolescent development and transitions into adulthood. Yet, communities must go beyond programs that target problem behaviors because, as our results show, adolescents can be arrested for reasons beyond their control, including their parents' arrest histories and socioeconomic status. 
Community involvement projects may also facilitate broader violence reduction efforts to reduce adolescent exposure to violence, which will also protect against problem behaviors and promote positive development [90]. Parent training has also been found to reduce delinquency and substance use among youth ([31]; [62]), and culturally based programs may be particularly warranted. Generations of forced removal of indigenous children from their homes into boarding schools and foster care systems has caused enduring damage to traditional parenting approaches, and reestablishing traditional models would have benefits to families and communities [25].

Additional research that investigates the circumstances surrounding arrest and police contact for these youth is very important for improving our understanding of why indigenous adolescents are disproportionately involved in the justice system. They often fall under multiple jurisdictions (i.e., tribal, state, and/or federal) depending on the type and location of the offense, whether the victim was a tribal member, and the presence of a tribal police force on their reservation/reserve [66]. Cabaniss et al. [9] describe several recommendations to reduce and ameliorate effects of arrest, including cultural competence training for police, judges, and other decision makers, and making it easier for caretakers to navigate the juvenile justice process. Communities and their young residents would benefit substantially if effective strategies can be employed to prevent arrest and reduce further involvement in the juvenile justice system.

Acknowledgments This research was funded by the National Institute on Drug Abuse (DA13580), the National Institute of Mental Health (MH67281), and the National Institute on Alcohol Abuse and Alcoholism (AA020299), Les B. Whitbeck, Principal Investigator.

\section{References}

1. American Indian Policy Center (2005). Alcohol/drugs and crime. http:/www.airpi.org/research/ SearchingforJustice/sjfindcauses/sjfalco.htm. Accessed 1 May 2005.

2. Apel, R., \& Kaukinen, C. (2008). On the relationship between family structure and antisocial behavior: parental cohabitation and blended households. Criminology, 46, 35-70.

3. Bachman, R. (1992). Death and violence on the reservation: homicide, family violence, and suicide in American Indian populations. New York: Auburn House.

4. Beauvais, F. (1992). The consequences of drug and alcohol use for Indian youth. American Indian and Alaska Native Mental Health Research, 5(1), 32-37.

5. Bishop, D. M. (2005). The role of race and ethnicity in juvenile justice processing. In Our children, their children: confronting racial and ethnic differences in American juvenile justice (pp. 23-82). Chicago: The University of Chicago Press.

6. Bishop, D. M., \& Frazier, C. E. (1996). Race effects in juvenile justice decision-making: findings of a statewide analysis. The Journal of Criminal Law and Criminology (1973-), 86(2), 392-414.

7. Brame, R., Bushway, S. D., Paternoster, R., \& Turner, M. G. (2014). Demographic patterns of cumulative arrest prevalence by ages 18 and 23. Crime and Delinquency, 60(3), 471-486.

8. Bureau of Indian Affairs. (2005). 2005 American Indian population and labor force report. United States Department of the Interior. http:/www.bia.gov/cs/groups/public/documents/text/idc-001719.pdf. Accessed 20 May 2014.

9. Cabaniss, E. R., Frabutt, J. M., Kendrick, M. H., \& Arbuckle, M. B. (2007). Reducing disproportionate minority contact in the juvenile justice system: promising practices. Aggression and Violent Behavior, 12(4), 393-401.

10. Caudill, J. W., Morris, R. G., Sayed, S. E., Yun, M., \& DeLisi, M. (2013). Pathways through the juvenile justice system: predictors of formal disposition. Youth Violence and Juvenile Justice, 11(3), 183-195. 
11. Centers for Disease Control and Prevention. (2013). Youth risk behavior system. Retrieved from http://www.cdc.gov/HealthyYouth/yrbs/index.htm.

12. Chartrand, L., \& McKay, C. (2006). A review of research on criminal victimization and First Nations, Métis and Inuit Peoples 1990 to 2001. Department of Justice Canada. http://www.justice.gc.ca/eng/rppr/aj-ja/rr06_vic1/rr06_vic1.pdf. Accessed 25 April 2014.

13. Chauhan, P., \& Reppucci, N. D. (2009). The impact of neighborhood disadvantage and exposure to violence on self-report of antisocial behavior among girls in the juvenile justice system. Journal of Youth and Adolescence, 38(3), 401-416.

14. Cheadle, J. E., \& Sittner Hartshorn, K. J. (2012). Marijuana use development over the course of adolescence among North American indigenous youth. Social Science Research, 41(5), 1227-1240.

15. Chin, G. J. (2002). Race, the war on drugs, and the collateral consequences of criminal conviction. Journal of Gender, Race and Justice, 6, 253-278.

16. Correctional Service of Canada. (2013). Demographic overview of aboriginal peoples in Canada and aboriginal offenders in federal corrections. http://www.csc-scc.gc.ca/aboriginal/002003-1008-eng.shtml. Accessed 2 February 2014.

17. Cottle, C. C., Lee, R. J., \& Heilbrun, K. (2001). The prediction of criminal recidivism in juveniles: a metaanalysis. Criminal Justice and Behavior, 28(3), 367-394.

18. Crutchfield, R. D., Skinner, M. L., Haggerty, K. P., McGlynn, A., \& Catalano, R. F. (2009). Racial disparities in early criminal justice involvement. Race and Social Problems, 1(4), 218-230.

19. Davis, J., \& Sorensen, J. R. (2013). Disproportionate minority confinement of juveniles: a national examination of black-white disparity in placements, 1997-2006. Crime and Delinquency, 59(1), 115-139.

20. DeJong, C., \& Jackson, K. C. (1998). Putting race into context: race, juvenile justice processing, and urbanization. Justice Quarterly, 15(3), 487-504.

21. DeLisi, M. (2006). Zeroing in on early arrest onset: results from a population of extreme career criminals. Journal of Criminal Justice, 34(1), 17-26.

22. Dixon, A., Howie, P., \& Starling, J. (2004). Psychopathology in female juvenile offenders. Journal of Child Psychology and Psychiatry, 45(6), 1150-1158.

23. Eitle, D., \& Turner, R. J. (2002). Exposure to community violence and young adult crime: the effects of witnessing violence, traumatic victimization, and other stressful life events. Journal of Research in Crime and Delinquency, 39(2), 214-237.

24. Elliott, D. S., \& Menard, S. (1996). Delinquent friends and delinquent behavior: temporal and developmental patterns. In J. D. Hawkins (Ed.), Delinquency and crime: current theories (pp. 28-67). Cambridge: Cambridge University Press.

25. Evans-Campbell, T. (2008). Historical trauma in American Indian/native Alaska communities: a multilevel framework for exploring impacts on individuals, families, and communities. Journal of Interpersonal Violence, 23(3), 316-338.

26. Fagan, J., \& Davies, G. (2000). Street stops and broken windows: terry, race, and disorder in New York City. Fordham Urban Law Journal, 28, 457.

27. Fagan, J., Geller, A., Davies, G., \& West, V. (2009). Street stops and broken windows revisited: the demography and logic of proactive policing in a safe and changing city. In S. K. Rice \& M. D. White (Eds.), Race, ethnicity, and policing: new and essential readings. New York: New York University Press.

28. Farrington, D. P. (2011). Families and crime. In J. Q. Wilson \& J. Petersilia (Eds.), Crime and public policy (pp. 130-157). New York: Oxford University Press.

29. Farrington, D. P., Barnes, G. C., \& Lambert, S. (1996). The concentration of offending in families. Legal and Criminological Psychology, 1(1), 47-63.

30. Farrington, D. P., Loeber, R., Stouthamer-Loeber, M., Van Kammen, W. B., \& Schmidt, L. (1996). Selfreported delinquency and a combined delinquency seriousness scale based on boys, mothers, and teachers: concurrent and predictive validity for African-Americans and Caucasians. Criminology, 34(4), 493-517.

31. Farrington, D. P., \& Welsh, B. C. (2007). Saving children from a life of crime. New York: Oxford University Press.

32. Federal Bureau of Investigation. (2013). Persons arrested-crime in the United States 2012. U.S. Department of Justice. http:/www.fbi.gov/about-us/cjis/ucr/crime-in-the-u.s/2012/crime-in-the-u.s.-2012 /persons-arrested/persons-arrested. Accessed 12 May 2014.

33. Felson, R. B., \& Staff, J. (2010). The effects of alcohol intoxication on violent versus other offending. Criminal Justice and Behavior, 37(12), 1343-1360.

34. Freudenburg, W. R. (1986). The density of acquaintanceship: an overlooked variable in community research? American Journal of Sociology, 92(1), 27-63.

35. Greenfeld, L. A., \& Smith, S. K. (1999). American Indians and crime. Washington, DC: Bureau of Justice Statistics. 
36. Hartney, C. (2008). Native American Youth and the juvenile justice system. National Council on Crime and Delinquency. http://www.nccd-crc.org/nccd/pubs/2008_Focus_NativeAmerican.pdf. Accessed 7 February 2009.

37. Hawkins, J. D., Herrenkohl, T. I., Farrington D. P., Brewer, D., Catalano, R. F., Harachi, T. W., et al. (2000). Predictors of youth violence. Juvenile Justice Bulletin. http://eric.ed.gov/?id=ED440196. Accessed 29 July 2014.

38. Henry, B., Caspi, A., Moffitt, T. E., \& Silva, P. A. (1996). Temperamental and familial predictors of violent and nonviolent criminal convictions: age 3 to age 18. Developmental Psychology, 32(4), 614-623.

39. Huizinga, D., \& Henry, K. L. (2008). The effect of arrest and justice system sanctions on subsequent behavior: findings from longitudinal and other studies. In A. M. Liberman (Ed.), The long view of crime: a synthesis of longitudinal research (pp. 220-254). New York: Springer.

40. Huizinga, D., Elliott, D. S., \& Dunford, F. W. (1986). The effect of arrest on subsequent delinquent behavior. In Boulder, CO: Paper presented at the Annual Meetings of the Academy of Criminal Justice Sciences, Orlando Florida. National Youth Survey Report, Behavioral Research Institute.

41. Huizinga, D., Thornberry, T., Knight, K., \& Lovegrove, P. (2007). Disproportionate minority contact in the juvenile justice system: a study of differential minority arrest/referral to court in three cities. Washington, DC: U.S. Department of Justice.

42. James, D. J. (2004). Profile of jail inmates, 2002. Washington, DC: U.S. Department of Justice, Bureau of Justice Statistics.

43. Jensen, E. L., Gerber, J., \& Mosher, C. (2004). Social consequences of the war on drugs: the legacy of failed policy. Criminal Justice Policy Review, 15(1), 100-121.

44. Jolliffe, D., Farrinton, D., Hawkins, J. D., Catalano, R. F., Hill, K. G., \& Kosterman, R. (2003). Predictive, concurrent, prospective and retrospective validity of self-reported delinquency. Criminal Behaviour and Mental Health, 13(3), 179-197.

45. Juby, H., \& Farrington, D. P. (2001). Disentangling the link between disrupted families and delinquency. British Journal of Criminology, 41(1), 22-40.

46. Kempf-Leonard, K. (2007). Minority youths and juvenile justice disproportionate: minority contact after nearly 20 years of reform efforts. Youth Violence and Juvenile Justice, 5(1), 71-87.

47. Kirk, D. S., \& Sampson, R. J. (2013). Juvenile arrest and collateral educational damage in the transition to adulthood. Sociology of Education, 86(1), 36-62.

48. Latimer, J., \& Foss, L. C. (2004). A one-day snapshot of aboriginal youth in custody across Canada: Phase II. Ottawa, Ontario: Department of Justice Canada. http://www.justice.gc.ca/eng/rp-pr/cj-jp/yj-jj/yj2-jj2 /index.html. Accessed 26 April 2014.

49. Leventhal, T., \& Brooks-Gunn, J. (2000). The neighborhoods they live in: the effects of neighborhood residence on child and adolescent outcomes. Psychological Bulletin, 126(2), 309-337.

50. Lopes, G., Krohn, M. D., Lizotte, A. J., Schmidt, N. M., Vasquez, B. E., \& Bernburg, J. G. (2012). Labeling and cumulative disadvantage: the impact of formal police intervention on life chances and crime during emerging adulthood. Crime and Delinquency, 58(3), 456-488.

51. Matsueda, R. L., \& Anderson, K. (1998). The dynamics of delinquent peers and delinquent behavior. Criminology, 36(2), 269-308.

52. May, P. A. (1996). Overview of alcohol abuse epidemiology for American Indian populations. In G. D. Sandefur, R. R. Rindfuss, \& B. Cohen (Eds.), Changing numbers, changing needs: American Indian demography and public health (pp. 235-256). Washington, DC: National Academy Press.

53. May, P. A. (2003). Binge drinking in the northern plains tribes. National Institute of Justice Journal, 249, 30-31.

54. McCord, J., Widom, K. S., \& Crowell, N. A. (2001). Juvenile crime, juvenile justice. Washington, DC: National Academy Press.

55. Miech, R. A., Johnston, L. D., O’Malley, P. M., Bachman, J. G., \& Schulenberg, J. E. (2015). Monitoring the future national survey results on drug use, 1975-2014: Volume 1, Secondary School Students. Ann Arbor, MI: Institute for Social Research. Retrieved from http://www.monitoringthefuture. org/pubs/monographs/mtf-vol1_2014.pdf.

56. Moffitt, T. E. (1993). Adolescence-limited and life-course-persistent antisocial behavior: a developmental taxonomy. Psychological Review, 100(4), 674-701.

57. Morash, M. (1984). Establishment of a juvenile police record. Criminology, 22(1), 97-111.

58. Murray, J., \& Farrington, D. P. (2010). Risk factors for conduct disorder and delinquency: key findings from longitudinal studies. Canadian Journal of Psychiatry, 55(10), 633-642.

59. Muthén, B., \& Masyn, K. (2005). Discrete-time survival mixture analysis. Journal of Educational and Behavioral Statistics, 30(1), 27-58. 
60. Muthén, L. K., \& Muthén, B. O. (1998-2010). Mplus User's Guide: Statistical Analysis with Latent Variables: User's Guide. Sixth Edition. Los Angeles, CA:Muthén \& Muthén.

61. Palamara, F., Cullen, F. T., \& Gersten, J. C. (1986). The effect of police and mental health intervention on juvenile deviance: specifying contingencies in the impact of formal reaction. Journal of Health and Social Behavior, 27(1), 90-105.

62. Patterson, G. R., \& Stouthamer-Loeber, M. (1984). The correlation of family management practices and delinquency. Child Development, 1299-1307.

63. Patterson, G. R., DeBaryshe, B. D., \& Ramsey, E. (1989). A developmental perspective on antisocial behavior. The American Psychologist, 44(2), 329-335.

64. Patterson, G. R., Forgatch, M. S., Yoerger, K. L., \& Stoolmiller, M. (1998). Variables that initiate and maintain an early-onset trajectory for juvenile offending. Development and Psychopathology, 10(3), 531547.

65. Perry, S. W. (2004). American Indians and crime - a BJS statistical profile, 1992-2002. U.S. Department of Justice, Bureau of Justice Statistics.

66. Perry, S. W., Malega, R., \& Banks, D. (2011). State prosecutors' offices with jurisdiction in Indian country, 2007. Compendium of Tribal Crime Data, 2011, 21-26.

67. Plunkett, M., \& Mitchell, C. M. (2000). Substance use rates among American Indian adolescents: regional comparisons with monitoring the future high school seniors. Journal of Drug Issues, 30(3), 575-591.

68. Pope, C. E., \& Snyder, H. N. (2003). Race as a factor in juvenile arrests. Washington, DC: Office of Juvenile Justice and Delinquency Prevention. http://cj-resources.com/CJ Juvenile Justice pdfs/juvennile\%20justice\%20and\%20race\%20-\%20Pope\%20et\%20al\%202003.pdf. Accessed $1 \overline{2}$ December 2011.

69. Puzzanchera, C. (2009). Juvenile arrests 2008. Washington, DC: Office of Juvenile Justice and Delinquency Prevention.

70. Puzzanchera, C., \& Hockenberry, S. (2013). National disproportionate minority contact databook. The National Center for Juvenile Justice for the Office of Juvenile Justice and Delinquency Prevention. http://www.ojjdp.gov/ojstatbb/dmcdb/. Accessed 31 May 2014.

71. Rodriguez, N. (2007). Juvenile court context and detention decisions: reconsidering the role of race, ethnicity, and community characteristics in juvenile court processes. Justice Quarterly, 24(4), 629-656.

72. Rodriguez, N. (2010). The cumulative effect of race and ethnicity in juvenile court outcomes and why preadjudication detention matters. Journal of Research in Crime and Delinquency, 47(3), 391-413.

73. Rodriguez, N., Smith, H., \& Zatz, M. S. (2009). "Youth is enmeshed in a highly dysfunctional family system": exploring the relationship among dysfunctional families, parental incarceration, and juvenile court decision making. Criminology, 47(1), 177-208.

74. Rowe, D. C., \& Farrington, D. P. (1997). The familial transmission of criminal convictions. Criminology, 35(1), 177-202.

75. Sampson, R. J., \& Laub, J. H. (1993). Structural variations in juvenile court processing: inequality, the underclass, and social control. Law and Society Review, 27, 285-312.

76. Sampson, R. J., \& Lauritsen, J. L. (1997). Racial and ethnic disparities in crime and criminal justice in the United States. Crime and Justice: A Review of Research, 21, 311-374.

77. Schwalbe, C. S., Fraser, M. W., Day, S. H., \& Cooley, V. (2006). Classifying juvenile offenders according to risk of recidivism predictive validity, race/ethnicity, and gender. Criminal Justice and Behavior, 33(3), 305-324.

78. Shaffer, D., Fisher, P., Lucas, C. P., Dulcan, M. K., \& Schwab-Stone, M. E. (2000). NIMH diagnostic interview schedule for children version IV (NIMH DISC-IV): description, differences from previous versions, and reliability of some common diagnoses. Journal of the American Academy of Child and Adolescent Psychiatry, 39(1), 28-38.

79. Simons, R. L., Johnson, C., Beaman, J., Conger, R. D., \& Whitbeck, L. B. (1996). Parents and peer group as mediators of the effect of community structure on adolescent problem behavior. American Journal of Community Psychology, 24(1), 145-171.

80. Steffensmeier, D. F., \& Allan, E. (1995). Gender, age, and crime. In J. F. Sheley (Ed.), Handbook of contemporary criminology (pp. 83-114). New York: Wadsworth.

81. Stewart, E. A., Simons, R. L., \& Conger, R. D. (2002). Assessing neighborhood and social psychological influences on childhood violence in an African-American sample. Criminology, 40(4), 801-830.

82. Tanner-Smith, E. E., Wilson, S. J., \& Lipsey, M. W. (2013). Risk factors and crime. In F. T. Cullen \& P. Wilcox (Eds.), The oxford handbook of criminological theory, the oxford handbooks in criminology and criminal justice (pp. 89-111). New York: Oxford University Press.

83. Teplin, L. A., Abram, K. M., McClelland, G. M., Dulcan, M. K., \& Mericle, A. A. (2002). Psychiatric disorders in youth in juvenile detention. Archives of General Psychiatry, 59(12), 1133-1143. 
84. Thornberry, T. P., Freeman-Gallant, A., Lizotte, A. J., Krohn, M. D., \& Smith, C. A. (2003). Linked lives: the intergenerational transmission of antisocial behavior. Journal of Abnormal Child Psychology, 31(2), 171-184.

85. Thornberry, T. P., \& Krohn, M. D. (2000). The self-report method for measuring delinquency and crime. In D. Duffee (Ed.), Criminal justice 2000 (Measurement and analysis of crime and justice, Vol. Volume 4, pp. 33-84). Washington, DC: U.S National Institute of Justice.

86. United States Sentencing Commission. 2015. Native Americans in the federal offender population. Washington, DC. http://www.ussc.gov/sites/default/files/pdf/research-and-publications/quickfacts/Quick Facts Native American Offenders FY14.pdf. Accessed 15 June 2016.

87. Walker, S., Spohn, C., \& Delone, M. (2011). The color of justice: race, ethnicity, and crime in America. Cengage Learning.

88. Walters, K. L., \& Simoni, J. M. (2009). Decolonizing strategies for mentoring American Indians and Alaska natives in HIV and mental health research. American Journal of Public Health, 99(S1), S71-S76.

89. Webster, D. W., Gainer, P. S., \& Champion, H. R. (1993). Weapon carrying among inner-city junior high school students: defensive behavior vs aggressive delinquency. American Journal of Public Health, 83(11), 1604-1608.

90. Whitbeck, L. B., Walls, M., \& Sittner Hartshorn, K. J. (2014). Indigenous adolescent development: psychological, social and historical contexts. New York: Routledge.

91. White, H. R., \& Gorman, D. M. (2000). Dynamics of the Drug-Crime Relationship. In The nature of crime: continuity and change, vol. 1, Criminal Justice 2000. Washington, DC: U.S. Department of Justice, Office of Justice Programs, Office of Justice Programs. http://www.dldocs.stir.ac.uk/documents/02d.pdf. Accessed 12 May 2014.

92. Wiley, S. A. (2015). Arrested development: does the grade level at which juveniles experience arrest matter? Journal of Developmental and Life-Course Criminology, 1(4), 411-433.

93. Yessine, A. K., \& Bonta, J. (2009). The offending trajectories of youthful aboriginal offenders. Canadian Journal of Criminology and Criminal Justice, 51(4), 435-472. 